\title{
Refractive changes after scleral buckling surgery
}

\author{
Alterações refracionais após retinopexia com explante escleral
}

\author{
João Jorge Nassaralla Junior ${ }^{1}$ \\ BelquizRodriguezdo Amaral Nassaralla²
}

Trabalho realizado no Departamento de Retina e Vítreo do Instituto de Olhos de Goiânia - IOG.

${ }^{1}$ Médico Oftalmologista do Departamento de Retina e Vítreo do Instituto de Olhos de Goiânia - IOG; Doutor em Ciências da Saúde pela Universidade de Brasília UnB; Doutorando em Oftalmologia pela Universidade Federal de Minas Gerais - UFMG.

${ }^{2}$ Médica Oftalmologista do Departamento de Córnea e Cirurgia Refrativa do Instituto de Olhos de Goiânia IOG; Doutora em Oftalmologia pela Universidade Federal de Minas Gerais - UFMG.

Endereço para correspondência: João Nassaralla Rua L, $\mathrm{n}^{0} 53,12^{\circ}$ andar - Setor Oeste - Goiânia (GO) CEP 74120-050 - E-mail: nassaral@zaz.com.br

Recebido para publicação em 30.04.2002 Aceito para publicação em 23.01.2003

\begin{tabular}{|l|}
\hline ABSTRACT \\
\hline Purpose: A prospective study was conducted to compare the refractive \\
changes after three different types of scleral buckling surgery. Methods: \\
A total of 100 eyes of 100 patients were divided into three groups according \\
to the type of performed buckling procedure: Group 1, encircling scleral \\
buckling (42 patients); Group 2, encircling with vitrectomy (30 patients); \\
Group 3, encircling with additional segmental buckling (28 patients). \\
Refractive examinations were performed before and at 1, 3 and 6 months \\
after surgery. Results: Changes in spherical equivalent and axial length \\
were significant in all 3 groups. The amount of induced astigmatism was \\
more significant in Group 3. No statistically significant difference was \\
found in the amount of surgically induced changes between Groups 1 and \\
2, at any postoperative period. Conclusions: All three types of scleral \\
buckling surgery were found to produce refractive changes. A correlation \\
exists between additional segments and extent of refractive changes. \\
\hline
\end{tabular}

Keywords: Retinal detachment/surgery; Scleral buckling/adverse effects; Refraction/ ocular; Biometry

\section{INTRODUCTION}

During the past several years, our Retina Service and others ${ }^{(1)}$ have continued to use primarily solid implants with encircling bands. Only occasionally episcleral silicone rubber sponges are utilized. Changes in refraction are frequent after retinal detachment surgery. The surgical technique used appears to influence these changes. Hyperopia ${ }^{(2)}$ and hyperopic astigmatism may occur presumably by shortening the anteroposterior axis of the globe after scleral resections ${ }^{(1)}$. Scleral buckling procedures employing an encircling band generally are expected to produce an increase in myopia and myopic astigmatism ${ }^{(1,3)}$. Some authors ${ }^{(1,3-4)}$ have reported the development of high degrees of irregular astigmatism that persist over six months following the implantation of radially oriented episcleral sponges, but others have not found astigmatic changes ${ }^{(5-6)}$.

A prospective study was designed to compare the refractive changes after three different types of scleral buckling surgery. We particularly examined if the induced changes in the corneal shape and refractive astigmatism differed because of the type of scleral buckling procedure performed.

\section{METHODS}

A total of 100 eyes from 100 patients, 59 male and 41 female, with a mean age of 52 years (range, 18 to $79 \mathrm{yr}$ ) underwent scleral buckling surgery to treat rhegmatogenous retinal detachment. Surgeries were performed from March 1995 to August 2001 by one of the authors (JJNJ). According to the 
type of buckling procedure, the patients were divided into three groups: Group 1, encircling scleral buckling (42 patients); Group 2, encircling with vitrectomy (30 patients); Group 3, encircling with additional segmental buckling (28 patients), (Tab. 1). Ophthalmic examinations were performed before and at 1, 3 and 6 months after surgery.

Preoperative examinations included personal medical ocular history, vision and anatomic status of the fellow eye, best spectacle corrected visual acuity (BSCVA), corneal topography, keratometry, manifest and cycloplegic refraction, tonometry, slit-lamp microscopy, specular microscopy, A-scan echographic measurement of the axial length and a detailed fundus examination with the indirect binocular ophthalmoscope and scleral depression. Preoperative refractive error was taken from the patient's latest prescription in cases where refraction measurement was not possible. All examinations were performed on both eyes at each visit, thus enabling analysis of the reproducibility and consistency of the techniques by providing a control group for the non-study eyes.

Informed consent was obtained from all patients after they received a detailed description of the surgical procedure and its known risks.

The scleral buckling techniques used in this study are described as follows. The scleral buckling elements used were 3 or $5.5 \times 7.5 \mathrm{~mm}$ half-thickness sponges (Mira 504 and 507, Mira Inc, Waltham, MA) for radial buckling procedures and hard silicone elements, including a $0.75 \times 2.5 \mathrm{~mm}$ band (Mira 240) to encircle the globe and $2.5 \times 9 \mathrm{~mm}$ circumferential segmental elements (Mira 276). A single double-armed 4-0 black suture with $8 \mathrm{~mm}$ suture bites was used for radial sponge placement. The silicone sponge was sutured circumferentially for the portions that corresponded to retinal tears and the detachment area. The sutures usually were spaced 2.5 to 3.0 $\mathrm{mm}$ wider than the silicone sponges. The anterior edge of the encircling band was routinely located $3 \mathrm{~mm}$ posterior to the ora serrata, as judged by the location of the extraocular muscle insertions and transillumination characteristics. As for encircling, the posterior edge of the hard silicone band was located routinely $14 \mathrm{~mm}$ posterior to the surgical limbus. Mattress sutures with 5-0 Mercilene (Ethicon Johnson-Johnson, São Paulo, Brazil) were placed to groove the silicone elements. The anterior suture bites for a circumferential scleral buckle were taken along the line of the extraocular muscle insertions (corresponding to the ora serrata). In quadrants where a grooved element was not used, the encircling band was anchored using partial-thickness scleral tunnels. The buckling elements were indented so the external surface followed the usual contour of the adjacent sclera. The ends of the band were secured with a tantalum clip, usually just above the medial rectus muscle in the superonasal quadrant. The anterior portion of the superior oblique tendon insertion was trimmed when necessary to facilitate placement of a scleral buckle in the superotemporal quadrant. Cryopexy was performed routinely, with CT 901 (Alimed-Tec - São Paulo - Brazil) around the sclera corresponding to the retinal tears at an appropriate duration placed under an operating microscope. The subretinal fluid drainage was accomplished using either an endophotocoagulator or a 26-gauge needle after the choroid was exposed by a scleral dissection around $2.0 \mathrm{~mm}$ in length. A pars plana vitrectomy was performed using a Vítreo Cirúrgico $101 \mathrm{AR}$ vitreous cutter (Micro Medicina, Goiânia, GO). The $1.0 \mathrm{~mm}$ wide sclerotomies were made using a microvitreoretinal (MVR) blade from 3.0 to $4.0 \mathrm{~mm}$ posterior to the surgical limbus. The infusion line was sutured in the inferotemporal sclerotomy during operation. After vitrectomy, octafluoropropane $\left(\mathrm{C}_{3} \mathrm{~F}_{8}\right)$ was injected in all patients. Postoperatively, all patients were placed on cycloplegics (tropicamide 1\%) for approximately 1 month. Cycloplegic and later manifest refractions were carried out during the whole postoperative period during 6 months using the streak retinoscopy, trial frame, and lenses. All cylindrical correction was converted to the minus power. In aphakic patients, refraction was also carried out over the patient's aphakic glasses to maintain a similar vertex distance. Aphakic patients, without spectacles or who wore contact lenses, were refracted with a trial frame and the vertex distance recorded.

A paired two-tailed t-test was used to compare preoperative and postoperative measurements. Data were computed as mean \pm standard deviation. Differences in continuous data were analyzed by Student's t-test. A P value $<0.05$ was considered statistically significant.

\section{RESULTS}

The lens status was as follows: 65 phakic eyes, 2 aphakic eyes, 23 pseudophakic eyes. In the latter group, there was a

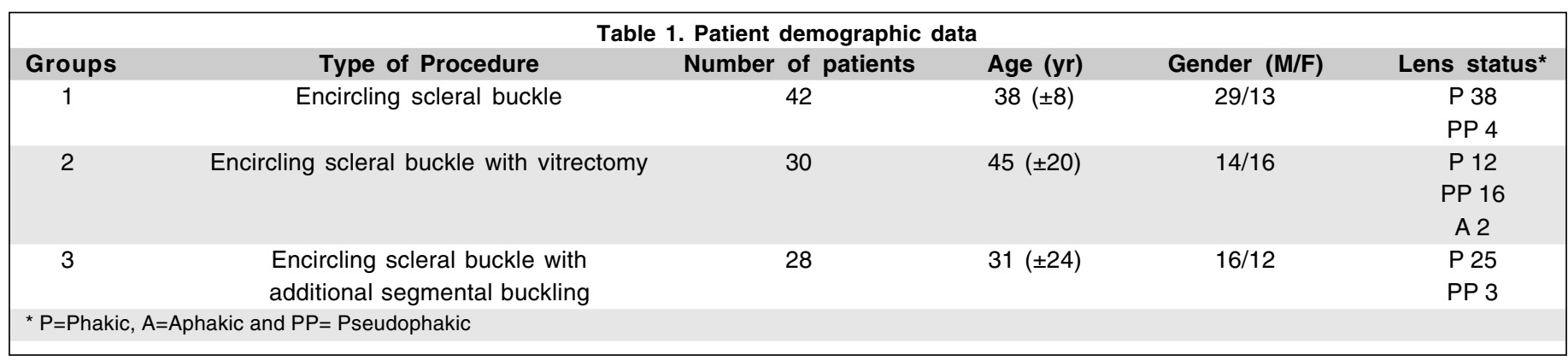


posterior chamber lens in all eyes with an intact posterior capsule in 15 patients and a capsulotomy in 8 eyes. No eye had anterior chamber intraocular lens. The macula was detached in $87(87 \%)$ eyes.

The preoperative best-corrected visual acuity was $20 / 40$ or better in 87 eyes $(87 \%), 20 / 50$ to $20 / 80$ in 15 eyes $(15 \%)$ and $20 / 100$ or worse in 8 eyes $(8 \%)$. Six months after surgery it was $20 / 40$ or better in 42 eyes (42\%), 20/50 to 20/80 in 36 eyes $(36 \%)$, and $20 / 100$ or worse in 22 eyes $(22 \%)$.

The difference between preoperative and postoperative refraction is compared between groups (Tab. 2, 3). Changes in refraction occurred in all patients after the three different types of scleral buckling surgery. These changes were usually found at the first postoperative refraction 1 month after surgery and persisted for up to 6 months. Statistical analysis did not show significant difference between the results found at 3 and 6 months after surgery (Tab. 2). Also, there was no statistically significant difference in the amount of induced myopia between phakic and aphakic eyes.

The mean spherical equivalent changed an average of $-1.00 \mathrm{D}$ in the eyes with encircling scleral buckle (Group 1), $-1.50 \mathrm{D}$ in the eyes with encircling scleral buckle plus vitrectomy (Group 2), and $-2.93 \mathrm{D}$ in the eyes with encircling scleral buckle plus additional segments (Group 3). Changes in the mean spherical equivalent were significant in all 3 groups $(\mathrm{P}<0.002)$. No statistical significance was found between Groups 1 and $2(\mathrm{P}=0.895), 1$ and $3(\mathrm{P}=0.322)$ and 2 and 3 $(\mathrm{P}=0.253)$.

The mean change in refractive cylinder, as measured by retinoscopy, was $0.11 \mathrm{D}$ in Group 1, $0.07 \mathrm{D}$ in Group 2, and 0.66 $\mathrm{D}$ in Group 3. The pattern of induced astigmatism as measured by retinoscopy paralleled the keratometric findings. Both retinoscopy and keratometry demonstrated significant induced

\begin{tabular}{|c|c|c|c|}
\hline \multicolumn{4}{|c|}{$\begin{array}{c}\text { Table 2. Mean }( \pm S D) \text { preoperative and postoperative spherical } \\
\text { equivalent }\end{array}$} \\
\hline Time & Group 1 & Group 2 & Group 3 \\
\hline Preoperative & $-1.00( \pm 3.68)$ & $-1.50( \pm 3.02)$ & $-2.93( \pm 2.60)$ \\
\hline 1 month & $-3.59( \pm 1.52)$ & $-2.92( \pm 3.00)$ & $-4.01( \pm 2.36)$ \\
\hline 3 months & $-2.95( \pm 1.71)$ & $-2.75( \pm 2.86)$ & $-3.73( \pm 1.85)$ \\
\hline 6 months & $-2.78( \pm 3.83)$ & $-2.67( \pm 3.40)$ & $-3.64( \pm 3.02)$ \\
\hline$p$ value & 0.000 & 0.000 & 0.002 \\
\hline
\end{tabular}

\begin{tabular}{|lccc|}
\hline \multicolumn{4}{|l|}{ Table 3. Mean $( \pm$ SD) } \\
Time & \multicolumn{2}{c|}{ preoperative and postoperative refractive } \\
cylinder & & \\
Preoperative & $-1.17( \pm 0.97)$ & $-0.84( \pm 0.74)$ & $-0.94( \pm 0.79)$ \\
1 month & $-1.73( \pm 1.11)$ & $-1.67( \pm 0.80)$ & $-1.98( \pm 1.58)$ \\
3 months & $-1.30( \pm 0.89)$ & $-1.06( \pm 0.47)$ & $-1.50( \pm 0.85)$ \\
6 months & $-1.28( \pm 1.06)$ & $-0.77( \pm 0.69)$ & $-1.50( \pm 1.06)$ \\
$p$ value & 0.175 & 0.526 & 0.000 \\
Student's t-test $p$ value $<0.05$ was considered statistically significant.
\end{tabular}

astigmatism related to the use of additional segments, although it was not influenced by the position of the scleral dissection. The amount of induced astigmatism was more significant in Group $3(\mathrm{P}=0.000)$ (Tab. 3$)$.

Regarding the axial length (Tab. 4), in this study we found an average increase of $1.2983 \mathrm{D}$ in the refractive error and 0.53 $\mathrm{mm}$ in the axial length. There was an average increase of $2.45 \mathrm{D}$ in spherical equivalent per each millimeter increase in axial length. The axial length increased an average of $0.42 \mathrm{~mm}$ in Group $1(\mathrm{P}=0.005), 0.62 \mathrm{~mm}$ in Group $2(\mathrm{P}=0.000)$, and $0.58 \mathrm{~mm}$ in Group $3(\mathrm{P}=0.000)$. No statistical significance was found between Groups 1 and 2 or 2 and 3 after surgery. A statistically significant difference between groups 1 and 3 was found before surgery $(\mathrm{P}=0.052)$ and after surgery this difference was higher $(\mathrm{P}=0.002)$.

Pearson correlation showed statistical significance $(\mathrm{P}=0.000)$ between the increase in spherical equivalent and axial length.

\section{DISCUSSION}

Postoperative changes in refraction are expected in the majority of patients following surgical procedures for retinal detachment. The surgical technique appears to influence these changes ${ }^{(2)}$. The episcleral-encircling buckle is utilized frequently at our institution. The most severe cases of distortion of the globe occur with additional segmental buckle.

Similar to other studies ${ }^{(3,7)}$ our data show a change in the refractive error after surgery. There was a tendency to induced astigmatism and myopia after scleral buckling procedures (Tab. 2, 3).

The probable mechanism for changing the refractive error is elongation of the globe by the pressure of equatorial band $^{(2)}$. However it may be possible to prevent an excessive induced refractive error. Smiddy ${ }^{(3)}$ found axial lengthening and corresponding induced myopia. In this study, the correlation between the increase in spherical equivalent and axial length was high $(\mathrm{P}=0.000)$. Lancaster ${ }^{(8)}$ states that an increase of $1 \mathrm{~mm}$ in axial length corresponds to a refractive change of 2.5 to $3 \mathrm{D}$. In our patients, there was an average increase of $2.45 \mathrm{D}$ of spherical equivalent per each increased millimeter in axial length.

Most studies have found induced myopia after scleral buckling surgery. The amount of increased axial length de-

\begin{tabular}{|c|c|c|c|}
\hline Time & Group 1 & Group 2 & Group 3 \\
\hline Preoperative & 23.94 & 24.14 & 24.68 \\
\hline 1 month & 26.14 & 26.32 & 25.02 \\
\hline 3 months & 25.62 & 26.13 & 24.92 \\
\hline 6 months & 24.36 & 24.76 & 25.26 \\
\hline$p$ value & 0.005 & 0.000 & 0.000 \\
\hline
\end{tabular}


pends on the height of encircling scleral buckle. The amount of induced myopia has been reported to be greater in phakic eyes than in aphakic eyes ${ }^{(3,5)}$. This is explained by an anterior displacement of the lens and optical considerations from refraction at spectacle plane ${ }^{(5,9)}$. Burton ${ }^{(4)}$ indicated that astigmatism may result from alteration of corneal curvature. In our study there was no statistical significant difference in the amount of induced myopia between phakic and aphakic eyes. To minimize the buckling-induced refraction changes, several recommendations may be made regarding scleral buckling procedures. Careful surgical planning and maneuvering are thus required to minimize the induced corneal astigmatism. The band should elevate easily 1 to $2 \mathrm{~mm}$ and not snap back to indent the globe. When abundant drainage of subretinal fluid and hypotony occurs ${ }^{(6)}$, it should be preferable to inject gas into the vitreous cavity site rather than to tighten the band excessively. This study was not designed to compare pneumatic retinopexy with conventional scleral buckling procedures, but candidates for pneumatic retinopexy are usually treated with a radial scleral buckle, instead of pneumatic retinopexy, although it may increase the risk of significant postoperative refractive error.

The refractive errors gradually diminished over the sixmonth follow up, with residual errors of -0.50 to -1.00 D remaining stable ${ }^{(4)}$. Grupposo ${ }^{(9)}$ reported on the refractive changes in 105 cases of retinal detachment. In his study, the largest spherical change was $-5.50 \mathrm{D}$ and the largest cylindrical change was $-4.00 \mathrm{D}$. Approximately $50 \%$ of patients had astigmatic errors greater than $0.50 \mathrm{D}$, but only $13 \%$ of the patients had errors that exceeded $-1.00 \mathrm{D}$. In our study the largest spherical change was $-3.75 \mathrm{D}$ and the largest cylindrical change was $2.5 \mathrm{D}$. In this study, $49 \%$ percent of patients had astigmatic errors greater than $0.50 \mathrm{D}$, and only $16 \%$ of our patients had astigmatic errors that exceeded $0.75 \mathrm{D}$.

High astigmatism following scleral buckling has been reported infrequently ${ }^{(7)}$. In our study irregular astigmatism was frequent. However, in most cases the induced corneal shape changes persisted for up to 6 months after surgery in a considerably irregular and asymmetric configuration. Induced changes in corneal shape decreased gradually over time. After encircling with additional segmental buckling, the refractive astigmatism axis corresponded to the segmental buckle ${ }^{(3)}$. These findings thus implied that segmental buckling may induce astigmatism, and this effect was greater when a buckle was placed closer to the cornea ${ }^{(2)}$. The encircling, intended to make an equal circular indentation of the eye, also produced a certain degree of corneal distortion and thus led to an irregular, but not statistically significant asymmetric astigmatism, 6 months after surgery.

\section{CONCLUSION}

In conclusion, all three types of scleral buckling surgery were found to produce refractive changes and increase axial length. A correlation exists between additional segments and extent of refractive change.

When a radial scleral buckle is used, the risk of significant induced changes in postoperative spherical equivalent is high. Because of an increased awareness in permanent refractive changes following scleral buckling, keratometry has become a part of the standard measurements of retinal detachment patients. In addition, the observation of continuous changes in refractive error during six months after surgery should prevent unnecessary prescriptions for glasses.

\section{RESUMO}

Objetivo: Estudo prospectivo foi realizado para comparar as alterações refracionais encontradas após três diferentes tipos de cirurgia com explante escleral. Métodos: Cem olhos de 100 pacientes foram divididos em 3 grupos de acordo com o tipo de cerclagem retiniana realizada: Grupo 1, cerclagem simples (42 pacientes); Grupo 2, cerclagem associada a vitrectomia (30 pacientes); Grupo 3, cerclagem associado a implante escleral segmentar (28 pacientes). Exames refracionais foram realizados antes e após 1, 3 e 6 meses da cirurgia. Resultados: A indução de astigmatismo foi maior no Grupo 3. Alterações no equivalente esférico e no diâmetro ântero-posterior foram significantes nos 3 grupos após a cirurgia. Nenhuma diferença estaticamente significativa foi encontrada nas alterações induzidas pela cirurgia entre os grupos 1 e 2 , em nenhum momento após a cirurgia. Conclusão: Os três tipos de retinopexia causam alteração refracional. Existe correlação entre a associação de segmentos à cerclagem e a intensidade da alteração refracional induzida.

Descritores: Descolamento retiniano/cirurgia; Recurvamento da esclera/efeitos adversos; Refração ocular; Biometria

\section{REFERENCES}

1. Burton TC, Herron BE, Ossoinig KC. Axial length changes after retinal detachment surgery. Am J Ophthalmol 1977;83:59-62.

2. Okada Y, Nakamura S, Kubo E, Oishi N, Takahashi Y, Akagi, Y. Analysis of changes in corneal shape and refraction following scleral buckling surgery. Jpn J Ophthalmol 2000;44:132-8

3. Smiddy WE, Loupe DN, Michels RG, Enger C, Glaser BM, deBustros S. Refractive changes after scleral buckling surgery. Arch Ophthalmol 1989; 107:1469-71.

4. Burton TC. Irregular astigmatism following episcleral buckling procedure with the use of silicone rubber sponges. Arch Ophthalmol 1973;90:447-8.

5. Rubin ML. The induction of refractive errors by retinal detachment surgery. Trans Am Ophthalmol Soc 1975;73:452-90.

6. Larsen JS, Syrdalen P. Ultrasonographic study on changes in axial eye dimensions after encircling procedure in retinal detachment surgery. Acta Ophthalmol (Copenh) 1979;57:337-43.

7. Hayashi H, Hayashi K, Nakao F, Hayashi F. Corneal shape changes after scleral buckling surgery. Ophthalmology 1997;104:831-7.

8. Lancaster W. Refraction and motility. Springfield: Charles C. Thomas; 1952. p. 149 .

9. Grupposo S. Visual results after scleral buckling with silicone implant. In: Schepens CL, Regan CDJ, editors. Controversial aspects of the management of retinal detachments. Boston: Little, Brown; 1965. p.354-63. 